\title{
Protective Activity of Aromatic Amines and Imines against Oxidative Nerve Cell Death
}

\author{
Bernd Moosmann ${ }^{1}$, Thomas Skutella ${ }^{2}$, Klaus \\ Beyer $^{3}$ and Christian Behl, ${ }^{1, *}$ \\ ${ }^{1}$ Max-Planck-Institute of Psychiatry, D-80804 Munich, \\ Germany \\ ${ }^{2}$ Neuroscience Research Center, Charité (Central \\ Campus), Humboldt University, D-10118 Berlin, Germany \\ ${ }^{3}$ Institute of Metabolic Biochemistry, University of \\ Munich, D-80336 Munich, Germany \\ ${ }^{*}$ Corresponding author
}

Oxidative stress is a widespread phenomenon in the pathology of neurodegenerative diseases such as Alzheimer's disease, Parkinson's disease, and amyotrophic lateral sclerosis. Neuronal cell death due to oxidative stress may causally contribute to the pathogeneses of these diseases. Therefore, neuroprotective antioxidants are considered to be a promising approach to slow down disease progression. We have investigated different aromatic amine and imine compounds for neuroprotective antioxidant functions in cell culture, and found that these compounds possess excellent cytoprotective potential in diverse paradigms of oxidative neuronal cell death, including clonal cell lines, primary cerebellar neurons, and organotypic hippocampal slice cultures. Aromatic amines and imines are effective against oxidative glutamate toxicity, glutathione depletion, and hydrogen peroxide toxicity. Their mode of action as direct antioxidants was experimentally confirmed by electron spin resonance spectroscopy, cell-free brain lipid peroxidation assays, and intracellular peroxide measurements. With half-maximal effective concentrations of 20-75 nM in different neuroprotection experiments, the aromatic imines phenothiazine, phenoxazine, and iminostilbene proved to be about two orders of magnitude more effective than common phenolic antioxidants. This remarkable efficacy could be directly correlated to calculated properties of the compounds by means of a novel, quantitative structure-activity relationship model. We conclude that bridged bisarylimines with a single free $\mathrm{NH}-$-bond, such as iminostilbene, are superior neuroprotective antioxidants, and may be promising lead structures for rational drug development.

Key words: Antioxidant/Cytoprotection/Free radical/ Neurodegeneration/Oxidative stress/Quantitative structure-activity relationship (QSAR).

\section{Introduction}

The occurrence of oxidative damage and an increased oxidative burden from free radical species appears to represent a recurrent hallmark of diverse neurodegenerative and neurological disorders (Simonian and Coyle, 1996). There is evidence that oxidative stress may constitute an essential part of the pathogenetic process, for example, in Alzheimer's disease (Multhaup et al., 1998; Behl, 1999; Christen, 2000), Parkinson's disease (Ebadi et al., 1996; Foley and Riederer, 2000), Huntington's disease (Browne et al., 1999), amyotrophic lateral sclerosis (Cookson and Shaw, 1999; Gurney, 2000), multiple sclerosis and other demyelinating diseases (Smith et al., 1999), cerebellar ataxias such as ataxia telangiectasia and Friedreich's ataxia (Kamsler et al., 2001; Palau, 2001), HIV neuropathy (Kaul et al., 2001), and prion diseases (Milhavet et al., 2000; Wong et al., 2000).

Neuronal cell dysfunction and cell death due to oxidative stress may causally contribute to the pathogeneses of these progressive diseases, but increased levels of free radical species also appear to be involved in more acute syndromes of neurodegeneration, such as neurotrauma, cerebral hemorrhage, and reperfusion injury after ischemic events (Dirnagl et al., 1999; Love, 1999; Parnham and Sies, 2000).

As a result of this widespread involvement of oxidative stress in neuronal dysfunction and the associated neurological disorders, the conclusion has been drawn that central, but also peripheral, nervous system cells are particularly vulnerable to oxidative imbalances, which might be a direct consequence of their unique topological architecture and the biochemical substrata they are built of (Floyd, 1999; Moosmann and Behl, 2000a; Shaw and Eggett, 2000). Consequently, neuroprotective antioxidants are being considered as a promising approach to slow down disease progression and to limit the extent of functional neuronal loss in chronic neurodegenerative disorders as well as after acute lesions of the brain.

To date, clinical evidence for a positive role of antioxidants in neurological disease is relatively scarce (Parkinson Study Group, 1993; Louwerse et al., 1995; Sano et al., 1997; Gutzmann and Hadler, 1998; Huntington Study Group, 1998; Shoulson, 1998; Ogawa et al., 1999; Grundman, 2000; Lodi et al., 2001; for a review, see Moosmann and Behl, 2001). Several of the less successful studies reported, however, may be readily explained from methodological inconsistencies, e. g., the use of compounds whose efficacy had not even been proven in the established animal or in vitro models of the disease, or from the administration of compounds with a rather 
unfavourable pharmacological profile, for example poor permeation of the blood-brain barrier (Vatassery et al., 1998; Grundman, 2000; Gilgun-Sherki et al., 2001; Moosmann and Behl, 2001). Nevertheless, results from standardized animal models, epidemiological studies, and from a wide array of biochemical considerations seem to indicate that certain investigational antioxidant compounds might have a profound preventive or therapeutic value (Sies, 1993; Baker et al., 1998; Parkes et al., 1998; Reiter, 1998; Leppala et al., 1999; Nourhashemi et al., 2000; Jung et al., 2001; and the above reviews). Consequently, the search for antioxidant pharmaceuticals which (i) inhibit pathogenetically relevant oxidative phenomena, (ii) readily pass the blood-brain barrier, and (iii) show a higher efficacy per dose, thereby concomitantly exhibiting a reduced risk of adverse side effects, is in the center of interest of clinically involved physicians as well as biochemically focused scientists (Harman, 1996; Behl, 1999; Prasad et al., 1999; Alexi et al., 2000; Grunblatt et al., 2000; Prasad et al., 2000; Sramek and Cutler, 2000; Wolozin and Behl, 2000; Gilgun-Sherki et al., 2001).

By employing relevant models of oxidative neuronal cell death, which have been successfully used in the assessment and potency ranking of phenolic antioxidants (Moosmann and Behl, 1999; Ishige et al., 2001), we have investigated the potential antioxidant cytoprotective effects of diverse aromatic amine and imine compounds. The pharmacological actions of the compounds are described on the basis of different cell biological systems (clonal cells lines, primary cell culture, and organotypic slice cultures), and they are functionally rationalized by effects exerted in biochemical and biophysical experiments. Finally, a quantitative structure-activity relationship model is presented, which directly links calculated molecular properties of the compounds to their protective effects in neuronal cell systems.

\section{Results}

\section{Aromatic Amines and Imines Protect Clonal and Primary Neurons from Oxidative Cell Death}

Several aromatic amines and imines, whose structures are shown in Figure 1, were investigated for their potential antioxidant and cytoprotective properties. As representative examples for the two classes of the amines and imines, the compounds 4-dodecylaniline and iminostilbene were selected, respectively. Figure 2 illustrates the potent neuroprotective effects of these compounds. While $2.5 \mathrm{~mm}$ glutamate leads to a complete loss of cell viability in the mouse hippocampal cell line HT22 via an oxidative cell death cascade (Figure 2D, E), the concomitant addition of $1 \mu \mathrm{m}$ 4-dodecylaniline (Figure 2G, H) or $100 \mathrm{~nm}$ iminostilbene (Figure $2 \mathrm{~J}, \mathrm{~K}$ ) results in an almost full prevention of the toxic effect, as assessed by phase contrast microscopy and propidium iodide staining. A similarly profound cytoprotective effect of the antioxidant

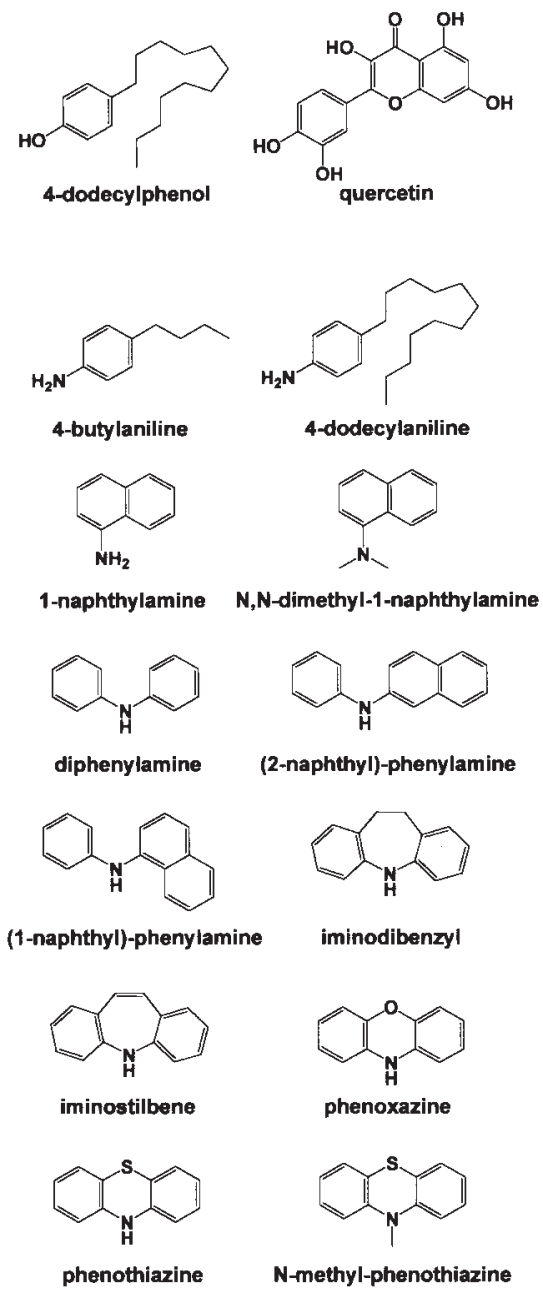

Fig. 1 Chemical Structures of the Aromatic Amines and Imines Used in This Study.

The aromatic amine and imine compounds that were investigated for neuroprotective activities are shown. The structures of two phenolic compounds are included for comparison.

drugs can be observed in rat primary cerebellar neurons (Figure 2, right column). These cells were set under oxidative stress by L-buthionine-[S,R]-sulfoximine (BSO)mediated inhibition of intracellular glutathione metabolism, which leads to the loss of neuritic structures and the disintegration of the cell bodies (Figure $2 \mathrm{~F}$ versus $\mathrm{C}$ ). Dodecylaniline as well as iminostilbene prevent these effects of glutathione depletion (Figure $2 \mathrm{I}$ and L).

\section{Organotypic Hippocampal Slice Cultures Are Rendered Resistant to Oxidative Stress by 4-Dodecylaniline and Iminostilbene}

In order to test these results in a cellular model closer to the in vivo situation, rat organotypic hippocampal slice culture, a method that leaves differentiated cells within their native connectivity patterns, was employed. Exposure to hydrogen peroxide results in widespread neuronal cell death among the cornu ammonis and the gyrus dentatus neurons of the hippocampus (Figure 3B versus A). The presence of dodecylaniline (Figure 3 C) or iminostil- 
A

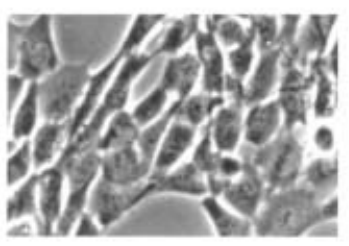

D

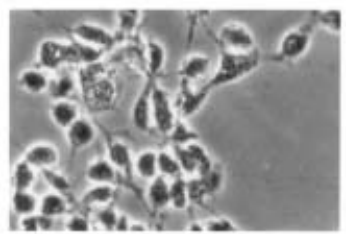

G

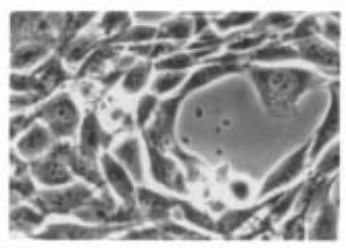

$\mathrm{J}$

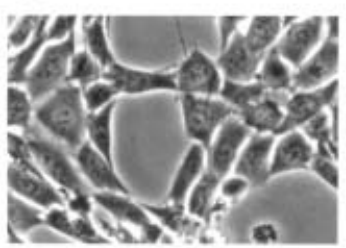

phase contrast
B

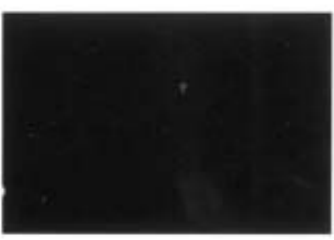

E

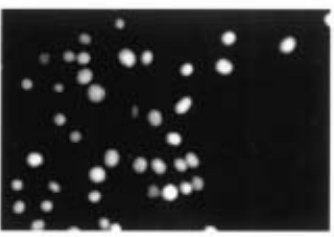

H

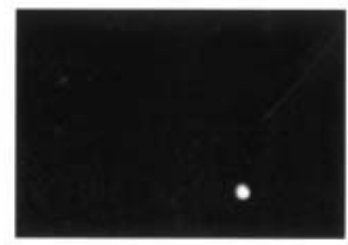

K

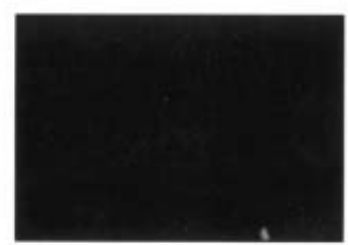

propidium iodide
C

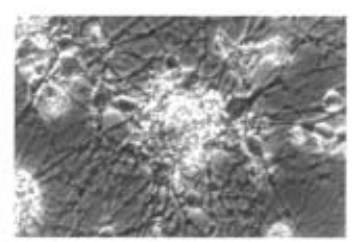

F

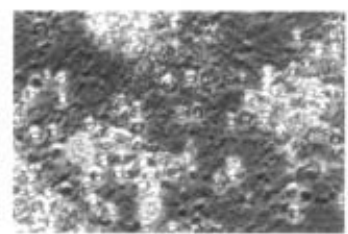

1

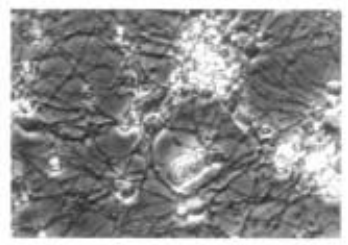

L

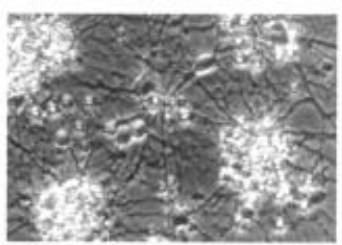

phase constrast

\section{cerebellar neurons}

Fig. 2 Antioxidant Neuroprotection by Aromatic Amines and Imines in Clonal and Primary Cell Culture.

Dodecylaniline and iminostilbene protect clonal hippocampal cells from oxidative glutamate toxicity and primary neurons from intracellular glutathione depletion. The left column shows phase contrast micrographs of mouse HT22 cells, the central column depicts fluorescence photographs of propidium iodide-stained cell cultures, corresponding to the cultures in the left column, and the right column shows rat primary cerebellar neurons. The first row shows the untreated positive controls, the second row the corresponding negative controls set under oxidative stress, and the third and fourth rows demonstrate the protective effects of $1 \mu \mathrm{m}$ 4-dodecylaniline and 100 nM iminostilbene, respectively. $2.5 \mathrm{~mm}$ glutamate was employed as toxin for the HT22 cells in (D) and (E) and the pictures below, leading to almost complete cell death after $24 \mathrm{~h}$. Cerebellar neurons were treated with $0.8 \mathrm{~mm}$ L-buthionine-[S,R]-sulfoximine (BSO) for 48 $h$, resulting in a collapse of the neurites and the lysis of the cell bodies $(F)$. In both of these oxidative stress paradigms, dodecylaniline $(\mathrm{G}-\mathrm{I})$ and iminostilbene $(\mathrm{J}-\mathrm{L})$ were able to revert the oxidative phenotype of the cells nearly to completion, as assessed by morphological evaluation (in the left and right columns), specific staining procedures (in the central column), and metabolic assays (shown in Figure 3). The high efficacy of the bisarylimine antioxidant iminostilbene at a concentration of only $100 \mathrm{~nm}$ is particularly remarkable. The photographs show areas of $200 \times 300 \mu \mathrm{m}$.

bene (Figure 3D) completely protects these neurons from the toxic effects of hydrogen peroxide overload.

\section{Aromatic Amines and Imines Are Effective in Diverse Cellular and Biochemical Systems, Counteract Various Oxidative Stressors, and Show Highly Reproducible Half-Maximal Effective Concentrations}

A quantitative analysis of the antioxidant effects of dodecylaniline and iminostilbene, illustrating the pharmacology and bandwidth of effect of these compounds, is shown in Figure 4. The cytoprotective effects of the substances against different toxins in HT22 cells are plotted in Figure $4 A-D$. The dose-response curves show that both compounds not only protect the cells from glutamate toxicity (Figure 4A), but also from the toxic effects of BSO (Figure $4 B$ ), hydrogen peroxide (Figure 4C), and tert-butyl hydroperoxide (Figure 4D). The half-maximal effective concentrations ( $E_{50}$ values) of each compound are very similar in all of these cases. The antioxidant cytoprotective effects of dodecylaniline and iminostilbene are also detectable in human neuronal cells (Figure 4E), peripheral fibroblasts (Figure 4F), and rat primary cerebellar neurons (Figure 4G), as qualitatively depicted in Figure 2. Figure 
A

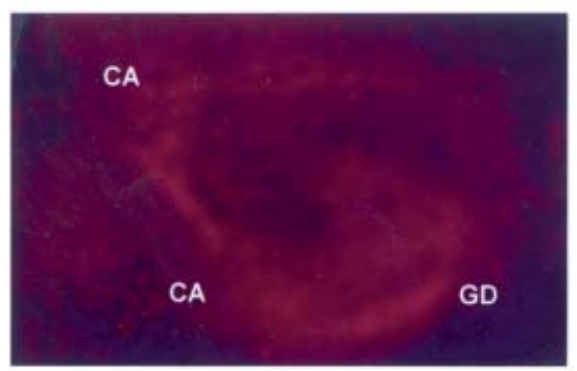

C

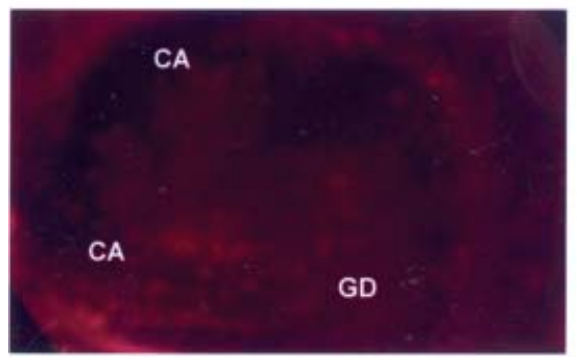

B

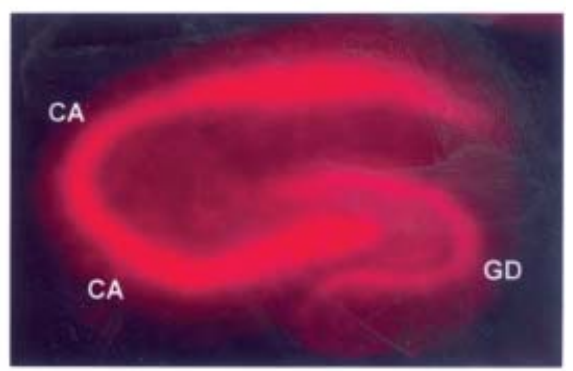

D

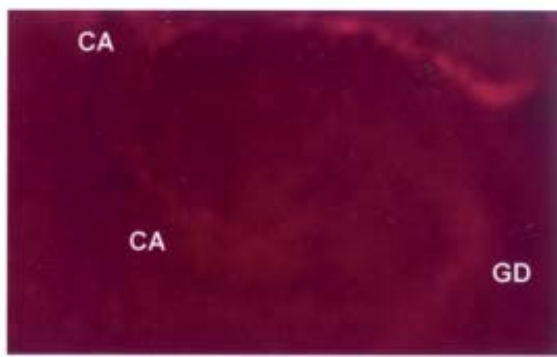

Fig. 3 Neuroprotective Effects of Aromatic Amines and Imines in Organotypic Hippocampal Slice Cultures.

After $72 \mathrm{~h}$ treatment with the oxidative neurotoxin hydrogen peroxide $(500 \mu \mathrm{m})$, propidium iodide staining reveals pronounced cell death in the gyrus dentatus (GD) and in the cornu ammonis (CA) regions of the hippocampus (B) as compared with untreated control cultures (A). The presence of 4-dodecylaniline $(10 \mu \mathrm{M} ; \mathrm{C})$ or iminostilbene $(1 \mu \mathrm{M}$; D) completely prevent this effect of hydrogen peroxide in hippocampal slice cultures. The photographs show areas of $2 \times 3 \mathrm{~mm}$.

$4 \mathrm{H}$ shows that both substances do not only rescue the cells from oxidative cell death, but they also suppress, during the preceding periods in the lethal oxidative cascade, the intracellular accumulation of peroxides as induced by BSO. Their antioxidant action therefore seems to correspond to their cytoprotective effect in HT22 cells. The idea that the compounds' antioxidative efficacy is due to a chemical structural activity is additionally suggested by results shown in Figure 4I. A cell-free, native rat brain lipid preparation is efficiently protected from peroxidation reactions. The direct inhibition of free-radical chain reactions, occuring during lipid peroxidation, may therefore be a major cause for the neuroprotective effects of dodecylaniline and iminostilbene. This notion is finally corroborated by kinetic experiments on glutamate toxicity in HT22 cells. Figure 4J shows that both compounds confer clear cytoprotection from glutamate toxicity even when added several hours after the toxin. Iminostilbene retains its full cytoprotective potential until approximately 8 hours after glutamate addition, which is immediately before cell membranes begin to lyse in the first cells. Dodecylaniline loses some of its protectivity before that time point, possibly due to a slower penetration of the cells. Nevertheless, when administered at that time point $(-8 \mathrm{~h})$, the half-maximal effective concentrations of the compounds are not altered (Figure 4K), indicating an identical mechanism of action at both time points $0 \mathrm{~h}$ (Figure 4A) and $-8 \mathrm{~h}$ (Figure $4 \mathrm{~K}$ ). The similarly antioxidant nature of the delayed protective action is demonstrated by the peroxide measurements in Figure 4L, which show that the delayed addition of both compounds to cells which have already accumulated increased levels of intracellular peroxides reduces this peroxide load significantly.

The dose-response curves in Figure 4 show that both compounds exhibit a highly reproducible antioxidant and cytoprotective behaviour, comprising many different cellular oxidative stress paradigms. Therefore, the two model systems of Figure 4A (glutamate toxicity in murine cells) and Figure 4E (peroxide toxicity in cells of human origin) were chosen for determining the half-maximal effective concentrations ( $\mathrm{EC}_{50}$ values) of all the compounds depicted in Figure 1. These results are shown in Table 1.

\section{The Free Nitrogen-Hydrogen (NH-) Bond Is Essential for the Observed Cytoprotective Effects}

All aromatic amines and imines with at least one free nitrogen-hydrogen (NH)-bond show some protective properties, with the less effective compounds exhibiting $\mathrm{EC}_{50}$ values between 1 and $10 \mu \mathrm{m}$, which is comparable to the characteristics of the two phenolic control compounds. Substances containing two aromatic ring systems, whether separated or linked, show higher efficacies, with the bridged compounds iminostilbene, phenoxazine and phenothiazine having the highest potencies and the lowest $\mathrm{EC}_{50}$ values of averaged 75,45 , and $20 \mathrm{~nm}$, respectively. Abrogation of the $\mathrm{NH}$-bonds leads to a loss of cytoprotective activity, as exemplified by the relative inefficiency of N,N-dimethyl-1-naphthylamine and $\mathrm{N}$ methyl-phenothiazine. Aromatic amines and imines therefore seem to constitute a whole class of cytoprotective antioxidants. 
A

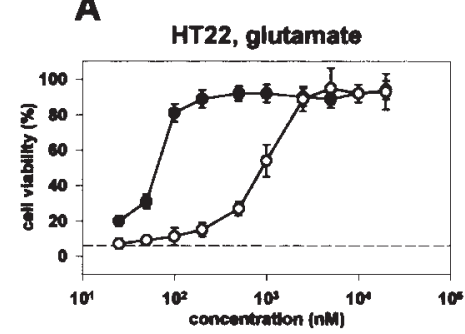

D

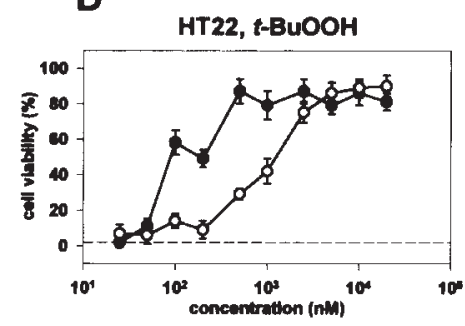

G

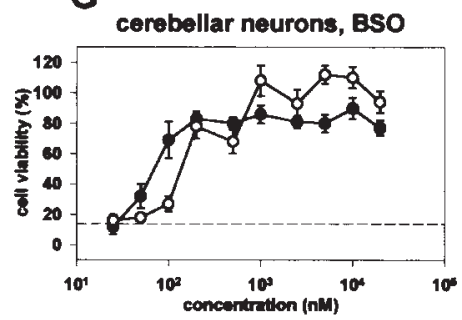

$\mathbf{J}$

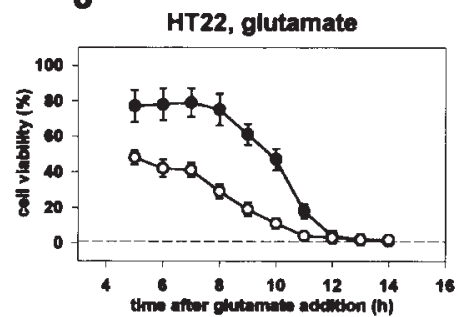

B

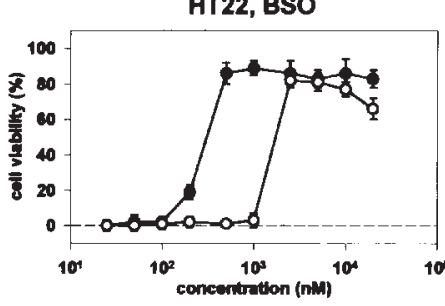

E

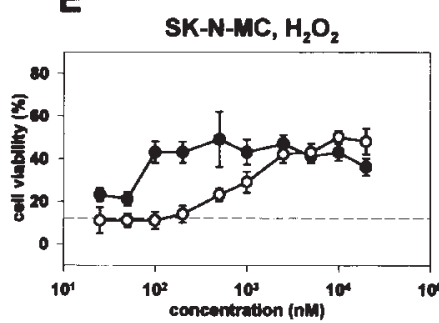

H

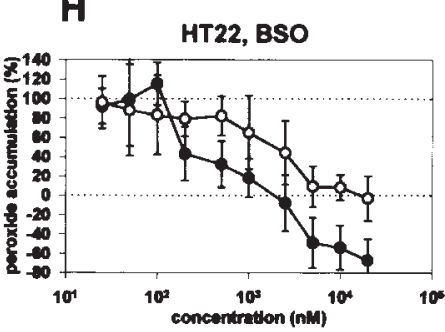

$\mathbf{K}$

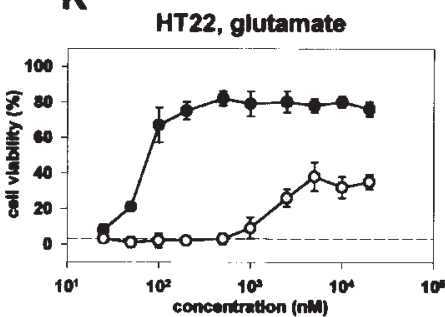

C

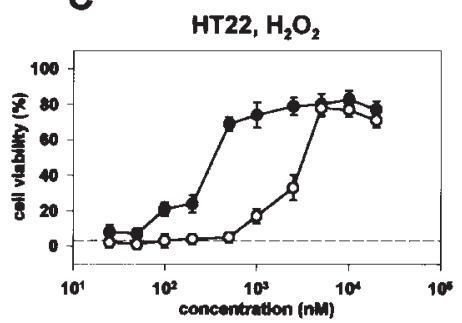

$\mathbf{F}$

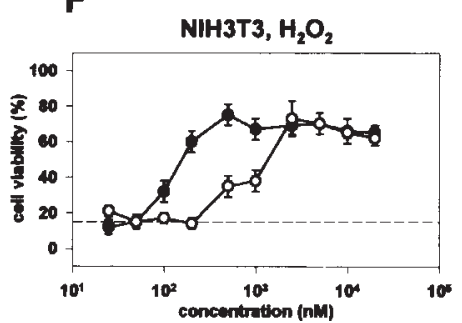

I

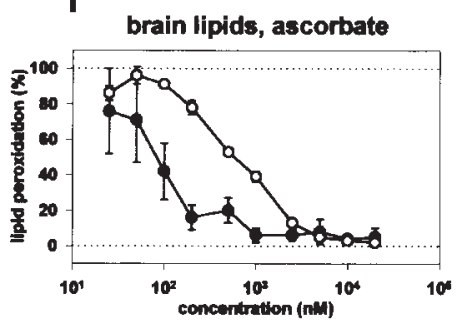

$\mathbf{L}$

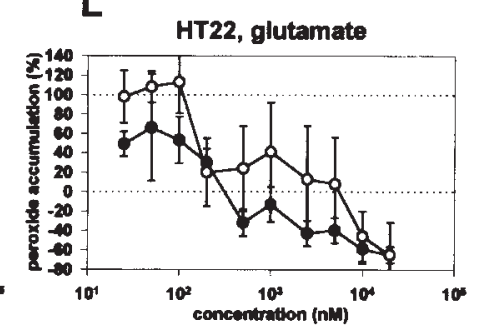

Fig. 4 Pharmacology and Bandwidth of Effect of the Two Compounds Dodecylaniline and Iminostilbene.

Dose-response curves of the antioxidant and cytoprotective effects of 4-dodecylaniline $(\bigcirc)$ and iminostilbene $(\bullet)$ in a variety of cell biological and biochemical paradigms. (A) Cytoprotective effect of dodecylaniline and iminostilbene in HT22 hippocampal cells challenged with glutamate $(2 \mathrm{~mm} ; 16 \mathrm{~h})$. Both compounds significantly enhance cell viability of the neuronal cells under these toxic doses of glutamate, administered comcomitantly with the latter. The half-maximal effective concentrations $\left(\mathrm{EC}_{50}\right.$ values) for the protective effect are, however, different for the two compounds, with a value of $70 \mathrm{~nm}$ for iminostilbene and $900 \mathrm{~nm}$ for dodecylaniline. The dashed line indicates the cell viability of the control cells treated with toxin alone. Panel (B) shows the effects of dodecylaniline and iminostilbene in HT22 cells depleted of intracellular glutathione by L-buthionine-[S,R]-sulfoximine (BSO) treatment (300 $\mu \mathrm{M} ; 24 \mathrm{~h})$; in (C) HT22 cells were challenged with hydrogen peroxide ( $180 \mu \mathrm{M} ; 16 \mathrm{~h})$; and in (D) the cells were incubated with tert-butyl hydroperoxide (30 $\mu \mathrm{M} ; 16 \mathrm{~h})$. Irrespective of the different oxidative toxins, both compounds exhibit pronounced cytoprotective effects with very similar $\mathrm{EC}_{50}$ values. These can further be reproduced in human neuronal SK-N-MC cells (E) (hydrogen peroxide $160 \mu \mathrm{M}$; $16 \mathrm{~h}$ ), mouse NIH3T3 fibroblasts (F) (hydrogen peroxide $250 \mu \mathrm{M} ; 16 \mathrm{~h}$ ), and in rat primary cerebellar neurons (G) (BSO $500 \mu \mathrm{m} ; 48 \mathrm{~h}$ ). The inhibition of cell death in HT22 cells is accompanied by a suppression of the pre-lethal intracellular accumulation of peroxides $(\mathrm{H})$ as induced by BSO (1 mM; $8 \mathrm{~h})$. Graph (I) shows that both compounds also significantly suppress brain lipid peroxidation (induced by $50 \mu \mathrm{m}$ ascorbate), with dose-response curves strongly resembling the cytoprotection dose-response curves. A kinetic analysis of the protective effect of the two compounds against glutamate toxicity $(2 \mathrm{mM})$ in HT22 cells, with a delayed addition of the antioxidants $(10 \mu \mathrm{M})$, reveals that both confer cytoprotection even when added several hours after the toxin $(\mathrm{J})$. A dose-response analysis for this delayed protection at the time point $-8 \mathrm{~h}$ is given in (K). (L) shows the intracellular peroxide load of HT22 cells pretreated with glutamate for $8 \mathrm{~h}$, followed by an additional incubation with glutamate and the antioxidants for $2 \mathrm{~h}$. This delayed addition of dodecylaniline and iminostilbene also leads to a significant reduction of the intracellular peroxide level.

In all cases, data are given as mean \pm s.e.m. Cell viability data were measured according to the MTT method at least in triplicate as described in Materials and Methods. The respective negative control cell viability is given as a dashed line. Concerning the biochemical data $(\mathrm{H}, \mathrm{I}, \mathrm{L})$, triplicate measurements were normalized to the corresponding positive and negative control values, which are indicated as dotted $0 \%$ and $100 \%$ lines. 
Table 1 Overview of the Quantitative Antioxidant Cytoprotective Properties of the Aromatic Amines and Imines, and of Some Control Compounds as Depicted in Figure 1.

\begin{tabular}{llc}
\hline & \multicolumn{2}{c}{$\mathrm{EC}_{50}$ value $(\mu \mathrm{M})$} \\
\cline { 2 - 3 } & $\mathrm{HT22}$ cells & SK-N-MC cells \\
\hline Quercetin & 4 & 4 \\
4-Dodecylphenol & 1.5 & 2.5 \\
4-Butylaniline & 8 & 6 \\
1-Naphthylamine & 4 & 4 \\
4-Dodecylaniline & 0.9 & 1.0 \\
Diphenylamine & 0.8 & 0.6 \\
(1-Naphthyl)-phenylamine & 0.4 & 0.4 \\
Iminodibenzyl & 0.3 & 0.3 \\
(2-Naphthyl)-phenylamine & 0.2 & 0.15 \\
Iminostilbene & 0.07 & 0.08 \\
Phenoxazine & 0.07 & 0.02 \\
Phenothiazine & 0.02 & 0.02 \\
N,N-dimethyl-1-naphthylamine & 80 & 100 \\
N-methyl-phenothiazine & 15 & 25 \\
\hline
\end{tabular}

The half-maximal effective concentrations ( $\mathrm{EC}_{50}$ values) of the compounds in two paradigms of antioxidant neuroprotection are shown. HT22 cells were treated with $2 \mathrm{mM}$ glutamate for $16 \mathrm{~h}$, and SK-N-MC cells were challenged with $160 \mu \mathrm{m}$ hydrogen peroxide for the same period of time, applying the antioxidant compounds concomitantly with the respective toxin. Cellular survival was subsequently quantified as described in Materials and Methods. The $\mathrm{EC}_{50}$ values were calculated from the results of ten different concentrations of every compound, each concentration measured at least in triplicate. Examples of cell survival graphs from which the $\mathrm{EC}_{50}$ constants were determined are shown in Figure 4. The potency of the aromatic compounds seems to be independent of the cell biological experimental system, but strongly linked to individual parameters of chemical structure.

\section{Iminostilbene Is a Direct Spin Quencher in Organic Solvents}

The inhibitory role of iminostilbene on free radical-mediated reactions was also demonstrated by electron spin resonance (ESR) spectroscopy, in order to verify the biochemical results. Using ethanol as solvent, N-tert-butyl$\alpha$-phenylnitrone (PBN) as a spin trap, and tert-butyl hydroperoxide as source of free radicals, iminostilbene drastically suppressed the formation of ESR-detectable PBN spin adducts (Figure 5). Even at a 500-fold lower molar concentration compared to PBN, iminostilbene still significantly quenches the nitrone paramagnetic signal (Figure 5F). Iminostilbene therefore directly and efficiently interacts with oxidizing free radical species.

\section{The Antioxidant Cytoprotective Potential of Aromatic Amines and Imines Can Be Predicted by Means of a Quantitative Structure-Activity Relationship (QSAR)}

In order to gain some insight into the structural causes for the very different $\mathrm{EC}_{50}$ values of the tested compounds in cell culture (Table 1), a number of structural properties of the compounds were calculated by computational chemistry. A multiple linear regression analysis approach was

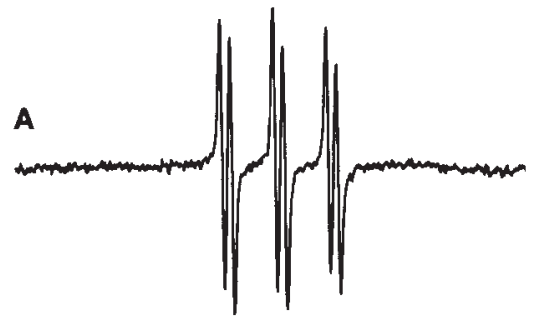

B
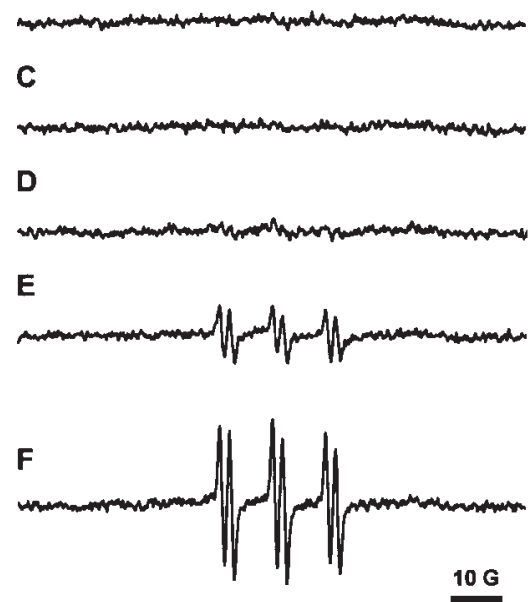

Fig. 5 Spin Quenching by Iminostilbene.

Electron paramagnetic resonance spectra of $\mathrm{N}$-tert-butyl- $\alpha$ phenylnitrone (PBN; $50 \mathrm{~mm}$ ) after oxidation with tert-butyl hydroperoxide $(t-\mathrm{BuOOH} ; 100 \mathrm{~mm})$ in ethanol with or without iminostilbene in different concentrations. (A) positive control, $(B)$ is above setting with $50 \mathrm{~mm}$ iminostilbene, (C) with $10 \mathrm{~mm}$, (D) with $2 \mathrm{~mm}$, (E) with $0.5 \mathrm{~mm}$, and $(\mathrm{F})$ with $0.1 \mathrm{~mm}$ iminostilbene. Even at a 500-fold lower concentration, iminostilbene significantly suppresses PBN spin adduct formation under the employed strongly prooxidant conditions (i. e. $100 \mathrm{~mm} t-\mathrm{BuOOH} ; 75^{\circ} \mathrm{C} ; 8 \mathrm{~h}$ ). The bar indicates $10 \mathrm{G}$.

used to identify those physico-chemical properties that are either directly correlated to or significantly influence their cytoprotective potential (Table 2). The main parameters to predict the protective potency of a compound were found to be (i) the difference of the heats of formation $\left(\Delta \mathrm{H}_{\mathrm{f}}\right)$ of a compound and its radical form, with a correlation coefficient of $r^{2}=0.675$, and (ii) the energy of this radical's lowest unoccupied molecular orbital [E(LUMOr); $\left.r^{2}=0.626\right]$. The respective radicals were formed in silico by the removal of a hydrogen atom at the functionally essential aromatic nitrogen atom (Figure 1). A mathematical combination of these two physico-chemical properties leads to a bilinear model for cytoprotective antioxidant action with an adjusted $r^{2}$ value of 0.787 (equation 1 in the Materials and Methods section). Two further factors of influence, optimizing this basis model, could be identified, i. e. (iii) the octanol/water partition coefficient ( $\log \mathrm{P})$, a generally employed measure of lipophilicity, and (iv) the spin density $[\sigma(N)]$ at the nitrogen atom after radicalization. A quadrufactorial linear model (equation 2) synthesized out of these four parameters, all of them directly 
Table 2 Calculated Molecular Parameters of the Antioxidant Compounds That Influence Their Cytoprotective Potential.

\begin{tabular}{|c|c|c|c|c|c|}
\hline & $\begin{array}{l}\text { (A) } \\
\text { Measured } \\
\ln \left(\mathrm{EC}_{50} / \mathrm{nm}\right)\end{array}$ & $\begin{array}{l}(\mathrm{B}) \\
\Delta \mathrm{H}_{\mathrm{f}} \\
{[\mathrm{kcal} / \mathrm{mol}]}\end{array}$ & $\begin{array}{l}\text { (C) } \\
\text { E(LUMOr) } \\
{[\mathrm{eV}]}\end{array}$ & $\begin{array}{l}\text { (D) } \\
\text { logP }\end{array}$ & $\begin{array}{l}(\mathrm{E}) \\
\sigma(\mathrm{N})\end{array}$ \\
\hline 4-Butylaniline & 8.853 & 40.56 & 0.3378 & 2.84 & 0.2519 \\
\hline 1-Naphthylamine & 8.294 & 39.50 & -0.2309 & 2.17 & 0.1742 \\
\hline 4-Dodecylaniline & 6.856 & 40.10 & 0.3349 & 6.48 & 0.2522 \\
\hline Diphenylamine & 6.551 & 41.80 & -0.3666 & 3.46 & 0.2997 \\
\hline (1-Naphthyl)-phenylamine & 5.991 & 35.86 & -0.5024 & 4.58 & 0.1975 \\
\hline Iminodibenzyl & 5.703 & 36.29 & -0.3430 & 3.94 & 0.2888 \\
\hline (2-Naphthyl)-phenylamine & 5.164 & 38.58 & -0.6994 & 4.58 & 0.2923 \\
\hline Iminostilbene & 4.317 & 35.46 & -1.2028 & 3.63 & 0.2405 \\
\hline Phenoxazine & 3.806 & 31.41 & -0.6545 & 1.98 & 0.2890 \\
\hline Phenothiazine & 2.995 & 24.99 & -0.7777 & 3.34 & 0.1863 \\
\hline
\end{tabular}

The measured neuroprotective potencies of the compounds are expressed in column (A) as the logarithm of the mean of the two $\mathrm{EC}_{50}$ values of neuroprotection listed in Table 1 (normalized to nanomolar units). Column (B) shows the difference of the calculated heats of formation $\left(\Delta \mathrm{H}_{\mathrm{f}} ; \mathrm{kcal} / \mathrm{mol}\right)$ of a parent compound and its radical form, the latter resulting from the abstraction of the nitrogen-bound hydrogen atom. Column $(C)$ is the energy (eV) of the respective radical's lowest unoccupied molecular orbital (LUMOr). Column (D) gives the octanol/water partition coefficient (logP) of each compound, and column (E) indicates the spin density $[\sigma(N)]$ at the nitrogen atom after radicalization by hydrogen abstraction.

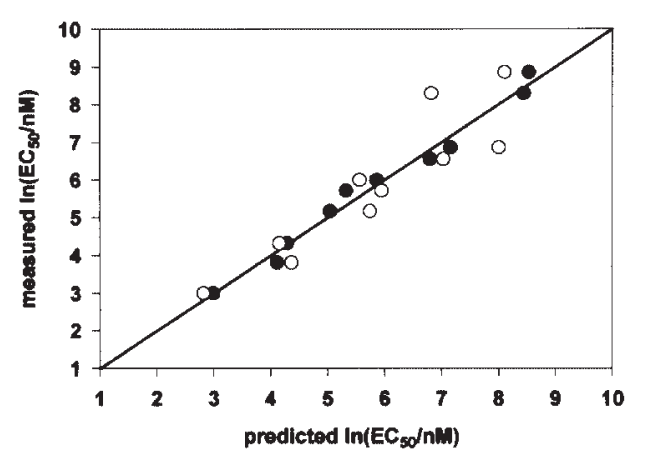

Fig. 6 Analysis of the Calculated Quantitative Models for Cytoprotective Antioxidant Action.

The measured $\ln \left(\mathrm{EC}_{50}\right)$ values are plotted against values calculated according to two predictive quantitative models of antioxidant action. Open circles $(\bigcirc)$ represent the bifactorial model which only employs $\Delta \mathrm{H}_{\mathrm{f}}$ and $\mathrm{E}(\mathrm{LUMOr})$ as determinants of the cytoprotective effect (equation 1); filled circles $(\mathbf{0})$ represent the quadrufactorial model of equation 2, which additionally takes into consideration logP and $\sigma(\mathrm{N})$. Both models can directly predict the protective behaviour of an antioxidant molecule in neuronal cell cultures.

amenable to calculation, reaches a predictive potency of $97 \%$. The model equations and their statistical evaluation are given in the Materials and Methods section. A visualization of the predictive potency of both models is depicted in Figure 6, comparing the directly measured cytoprotective $\operatorname{In}\left(E C_{50}\right)$ values, as derived from Table 1, with $\ln \left(E_{50}\right)$ values calculated according to the quantum chemical models. Especially the quadrufactorial model seems to represent a linearization of strong predictive value.

\section{Discussion}

Comparing the structures of the aromatic amines and imines shown in Figure 1 with their quantitative protective potencies listed in Table 1, some structural prerequisites of cytoprotective action can be derived. These can be divided into mandatory, essential structural moieties, and factors that enhance antioxidant activity. The basic building block of a cytoprotective aromatic amine is the aniline structure, and its cytoprotective function increases with increasing lipophilicity, as seen from the comparison of 4dodecylaniline with 4-butylaniline. The nature of the aromatic system bearing the nitrogen atom is the main determinant to enhance antioxidant activity. In this respect, as a single aromatic system naphthalene is not superior to benzene, but two aromatic moieties attached to the central nitrogen atom are generally superior to a single aromatic system. Further increases in antioxidative potency are produced by a bridging of the two aromatic rings (iminodibenzyl versus diphenylamine), an additional mesomeric coupling of the rings (iminostilbene versus iminodibenzyl), or a bridging of the rings with a heteroatom with lone electron pairs, such as oxygen or sulfur (phenoxazine and phenothiazine versus iminodiben$z y l)$. In general, imines are more potent than amines.

The presence of at least one single $\mathrm{NH}$-bond is the other essential prerequisite for antioxidant action: 1naphthylamine as well as phenothiazine, being very different in antioxidant potency, become almost inefficient upon methylation, $i$. e. the loss of their $\mathrm{NH}$-bonds (Figure 1 and Table 1). These findings, concerning the aromatic system and the $\mathrm{NH}$-bond, together with the bio- 
chemical assays in Figure 4 and the ESR measurements in Figure 5 imply that the homolytic dissociation of the $\mathrm{NH}$-bond, leading to an amine or imine radical, comprises the basic mechanism of cytoprotective action. On the basis of this hypothesis, and from the analogy to phenolic antioxidants, the quantum mechanical calculations summarized in Table 2 were performed.

A quantitative structure-activity relationship model was developed which employs exclusively intelligible parameters of molecular architecture with regard to the above radicalization hypothesis. This model reaches an adjusted correlation coefficient of 0.969 , which indicates that the essential physical properties required for antioxidant cytoprotective activity have been identified, and which strongly implies that the above hypothesis is indeed justified. It is remarkable that such a reliable correlation could be drawn directly between in silico data and measured cell biological effects of pathological relevance. With phenolic antioxidants similar approaches have been followed (Burton et al., 1980; van Acker et al., 1993), but they have generally linked calculated properties only to surrogate markers of antioxidant activity, such as the redox potential, or the reactivity of the compounds in model reactions of limited biological relevance (van Acker et al., 1996; Lien et al., 1999; Halliwell, 2000).

The chemical calculations also provide some quantitative insight into the structural enhancers of antioxidant activity. While the difference of the heats of formation, $\Delta H_{f}$, is especially reduced in the imine antioxidants, which finally seems to determine their superior antioxidant activity, a low LUMOr energy level apparently mirrors the aromatic stabilization of the nitrogen-based radical. The spin density at the nitrogen atom is, however, not directly correlated to antioxidant activity $\left(r^{2}=0.007\right)$, as deducible from the values in Table 2 or its unexpected negative contribution in equation 2 , but it seems to correct overrepresented influences of $\Delta \mathrm{H}_{\mathrm{f}}$ or $\mathrm{E}(\mathrm{LUMOr})$ in this equation. The fourth property, lipophilicity, as represented by the $\log \mathrm{P}$ value, further refines the model presented.

It has already been shown that positively charged ammonium groups impede antioxidant action in derivatives of phenothiazine (Yu et al., 1992); nevertheless lipophilicity has to be considered with care, as far as drug design is concerned. Neuroprotective agents should be able to penetrate the blood-brain barrier effectively, but very lipophilic compounds with long alkyl chain membrane anchors are usually excluded from passively entering the brain (Seelig et al., 1994; Moosmann and Behl, 2000b). Therefore, this factor might be overestimated in cell biological considerations.

Finally, the question arises of how to judge the potency of the aromatic imines with respect to other classes of antioxidants, keeping in mind the $\mathrm{EC}_{50}$ values of 20 to 75 nм for the three bridged and mesomerically coupled bisarylimines. We and others have tested many different antioxidants in identical cell biological systems to those described here, e. g. glutamate toxicity in HT22 cells, and we have found that among twenty natural or synthetic monophenolic compounds 4-dodecylphenol had the highest potency, with an $\mathrm{EC}_{50}$ value of $2 \mu \mathrm{m}$ (Moosmann et al., 1997; Moosmann and Behl, 1999). Ishige et al. (2001) have recently assayed approximately 25 polyphenolic flavonoid compounds in the same setting and found that the best structure, baicalein, exhibited an $\mathrm{EC}_{50}$ value of $1 \mu \mathrm{m}$, while most of the structures had no effect at all. The value for quercetin, which we have included for comparison (Table 1), was $3 \mu \mathrm{m}$. Recently, we have shown that diverse other types of antioxidants are either completely ineffective (such as bilirubin, $\beta$-carotene, and some lazaroids) or rather weak (thiol compounds) in protecting neuronal cells from oxidative stress (Moosmann and Behl, 2000a). Since the best phenolic antioxidants are therefore characterized by $\mathrm{EC}_{50}$ values that are two orders of magnitude higher than those of the best bisarylimines, the conclusion can be drawn that phenols seem to be generally inferior to imines with respect to antioxidant neuroprotection. In addition, the presented bisarylimines do not appear to constitute the best imaginable molecules yet, with respect to the calculated physico-chemical parameters shown in Table 2. We therefore assume that this structural class of compounds is clearly amenable to optimization by further rational chemical substitution of the aromatic rings of the shown lead structures, for example according to equation 2 . The presented lead molecules themselves might have further advantages such as their relatively low molecular weight, e. g. as compared to flavonoids, and their relatively high lipophilicity combined with an estimated high critical micellar concentration and a comparably low cross-sectional area at the lipid/water interface. These might all be favorable aspects of efficient blood-brain barrier permeation (Seelig et al., 1994; Fischer et al., 1998).

The cellular models employed to test the compounds for antioxidant neuroprotective effects are of high relevance for the phenomena occurring in neurodegenerative disease. Hydrogen peroxide (Figures 3 and 4) is a known toxin and inducer of apoptosis in Alzheimer's disease (Behl et al., 1994), and it is involved in nigral degeneration in Parkinson's disease (Ebadi et al., 1996). Superoxide dismutase (SOD)/catalase mimetics with a higher catalase activity but identical SOD activity are significantly more effective in rat models of focal ischemia (Baker et al., 1998), pointing toward an important role of hydrogen peroxide in ischemic neuronal cell death. Down's syndrome neurons have been described to exhibit elevated intracellular levels of peroxides and an increased degree of lipid peroxidation (Busciglio and Yankner, 1995). Intracellular glutathione depletion (Figures 2 and 4 ) is a major adverse consequence of cellular exposure to cytotoxic agents, and an early specific biochemical event in incidental Lewy body disease and Parkinson's disease (Gu et al., 1998; Sies, 1999). Excitotoxicity due to increased levels of the neurotransmitter glutamate constitutes a general hallmark of many neurodegenerative diseases, even if the mechanisms of cell death may vary among neuronal 
populations (Sattler and Tymianski, 2000). The presented cell biological data for the antioxidant neuroprotective effects of aromatic amines and imines might therefore be of high relevance to the situation in vivo and to the treatment of neurological disease.

In summary, we have investigated the neuroprotective effects of aromatic amine and imine compounds, employing diverse models of oxidative neuronal cell death which have been considered to be relevant to the oxidative pathogenetic processes occurring in several neurodegenerative diseases. We found that this class of lead structures contains examples of superior efficacy to protect neurons from oxidative apoptosis. The neuroprotective effects seem to occur under a variety of very different conditions of oxidative stress, but they can nevertheless be intimately linked to predictable chemical properties of the compounds. These results may open new avenues for neuroprotective drug design.

\section{Materials and Methods}

\section{Chemicals}

Chemicals and biochemicals were purchased from SigmaAldrich at the highest grade available. The antioxidant chemicals were from Sigma-Aldrich or from this supplier's Library of Rare Chemicals. In general, a purity of $97-99 \%$ was indicated. 4-Dodecylphenol was employed as a mixture of homologs (80\%). N-Methyl-phenothiazine (98\%) was recrystallized twice (ethanol:water 1:1; methanol:water 1:1) to remove potential contaminations, and was afterwards found to be pure according to analytical TLC.

\section{Cell Culture}

All media, sera, and supplements for cell culture were obtained from Gibco-BRL. Glutamate-sensitive murine hippocampal neurons (HT22) were a kind gift from P. Maher (The Scripps Research Institute, La Jolla, USA). Human neuroblastoma cells (SK-N-MC) and murine clonal fibroblasts (NIH3T3) were from the American Type Culture Collection. Clonal cell cultures were grown under standard conditions [Dulbecco's Modified Eagle Medium (DMEM) supplemented with $10 \%$ fetal calf serum (FCS) under $5 \% \mathrm{CO}_{2}$ atmosphere in a humidified $37^{\circ} \mathrm{C}$ incubator].

\section{Cerebellar Primary Neurons}

Newborn Sprague-Dawley (Charles River) rats were decapitated on post-natal day 3 to prepare dissociated neuronal cell cultures from cerebellum. The cerebella were cut into several pieces and were then incubated in Dulbecco's phosphate-buffered saline (D-PBS) containing $0.05 \%$ trypsin and $0.02 \%$ EDTA for 20 min at room temperature. Subsequently the tissue pieces were transferred to Hank's balanced salt solution (HBSS) supplemented with $10 \%$ fetal calf serum (FCS). The cells were dissociated by careful pipetting through a serological pipette, and remaining undissociated pieces were removed by filtration through a $50 \mu \mathrm{m}$ nybolt mesh (Eckert). After centrifugation ( $200 \mathrm{~g}, 4 \mathrm{~min}$ ), the cells were resuspended in Minimal Essential Medium (MEM) supplemented with $10 \%$ FCS and plated at a density of 50000 cells per well in 96-well plates. The plates had been precoated with a $0.01 \mathrm{mg} / \mathrm{ml}$ poly-L-lysine solution for $4 \mathrm{~h}$ (molecular weight range $70-150 \mathrm{kDa}$ ). After $36 \mathrm{~h}$ in culture, the cells were trans- ferred to serum-free conditions with the final culture medium MEM:F12 1:1 including N2 supplements, modified to finally contain $0.5 \mathrm{~nm}$ triiodothyronine and $5 \mathrm{~g} / \mathrm{l}$ glucose. Experiments were performed beginning $24 \mathrm{~h}$ after the change to serum-free conditions.

\section{Organotypic Hippocampal Slice Culture}

Eight to ten day old Sprague-Dawley rats were decapitated, the brains were removed and transferred to cold Minimal Essential Medium (MEM). A tissue chopper was used to cut the hippocampi into $400 \mu \mathrm{m}$ slices, which were placed on sterile, porous $0.4 \mathrm{~nm}$ membranes (Millipore). The membranes were then transferred to tissue culture plates covered with culture medium (MEM supplemented with 1\% FCS). The culture medium was changed two times per week. Slice cultures were used for experiments after 7 days in vitro.

\section{Cell Viability}

Cell viability experiments were generally done employing two measuring principles: colorimetric assays of metabolic activity [using the tetrazole 3-(4,5-dimethylthiazol-2-yl-)-2,5-diphenyltetrazolium bromide, MTT], and cell counts after staining for cell membrane permeabilized cells (employing the fluorescent DNA intercalator propidium iodide, $\mathrm{PI}$, and the azo-dye trypan blue, which leaves intact cells unstained as viewed by phase contrast microscopy). No significant discrepancies between the different methods to determine cell viability, with either clonal cell lines or primary neurons, could be observed.

For individual cell viability experiments, HT22 cells were plated at a density of 4000 cells per well (SK-N-MC cells: 20000 cells per well; NIH3T3 cells: 10000 cells per well) in 96-well culture dishes for $24 \mathrm{~h}$. Then the cytotoxins were added in the indicated concentrations. After the incubation, $0.5 \mathrm{mg} / \mathrm{ml}$ of the MTT reagent were applied to the cells for $2-8 \mathrm{~h}$, after which the cells were lysed by the addition of 1 volume of solubilization solution [40\% dimethylformamide (DMF), 10\% sodium dodecyl sulfate (SDS), pH 4.0 with acetic acid]. One day later, the plates were read with a Dynatech photometer at $550 \mathrm{~nm}$. For the propidium iodide measurements, the cells were incubated with 10 $\mu \mathrm{g} / \mathrm{ml}$ of the dye for $10 \mathrm{~min}$. After two washes with DMEM, the cell cultures were photographed employing phase contrast versus fluorescence optics (filter cut-off at $540 \mathrm{~nm}$ ). Quantification of cell survival was done by calculating the ratio of live/dead cells per culture plate area on the photographs.

As neurotoxins, L-glutamate, hydrogen peroxide $\left(\mathrm{H}_{2} \mathrm{O}_{2}\right)$, tertbutyl hydroperoxide $(t-\mathrm{BuOOH})$, and S-butylhomocysteine sulfoximine [L-buthionine-(S,R)-sulfoximine, BSO] were employed in the indicated concentrations, generally leading to a nearly complete loss of cell viability with the plating densities and incubation times used. All of these oxidative toxins were compared in HT22 cells, while in the other cell systems a representative selection of them would be applied. HT22 cells are a very well-established, reproducible model to investigate neuronal cell death (Tan et al., 1998). The antioxidants were generally added concomitantly with the respective toxins without preincubation as $100-$ or 200 -fold ethanolic solutions. For the kinetic experiments, antioxidants were added at the indicated time points after the addition of the toxin.

In the hippocampal slice culture experiments, propidium iodide (PI) was added to the cultures at a concentration of $5 \mu \mathrm{g} / \mathrm{ml}$ for $4-6 \mathrm{~h}$. PI is a fluorescent DNA label which selectively enters slice culture cells with permeable or lysed cell membrane. After the incubation, the slices were washed with fresh culture medium to remove excess PI. The cultures were then examined with an Olympus fluorescence microscope; PI fluorescence was 
evaluated using an excitation filter set at $470-490 \mathrm{~nm}$ and a barrier filter set at $515-550 \mathrm{~nm}$.

For the incubation of the slice cultures with hydrogen peroxide, $\mathrm{H}_{2} \mathrm{O}_{2}(500 \mu \mathrm{m})$ was added to the cultures every $24 \mathrm{~h}$ for a total of $72 \mathrm{~h}$ by exchanging the culture medium. The antioxidants were added to the cultures from $10^{-2} \mathrm{M}$ stock solutions in ethanol, and these or ethanol alone were analogously added to the culture medium every $24 \mathrm{~h}$ for a total of $72 \mathrm{~h}$ after the exchange of the medium.

\section{Peroxide Accumulation}

Neuronal HT22 cells seeded in 96-well dishes as described above were treated with buthionine sulfoximine (BSO; $1 \mathrm{mM}$ ) for $8 \mathrm{~h}$ and were afterwards loaded with $20 \mu \mathrm{m}$ dichlorofluorescin diacetate (DCFA) for $10 \mathrm{~min}$. DCFA is converted by intracellular hydrolysis to a fluorescent probe for peroxides and other oxidizing species. The DFCA-containing medium was removed, and the cells were covered with fresh DMEM after a washing step with the same medium. Cell-trapped fluorescence was measured with a Wallac fluorescence plate reader employing a $485 \mathrm{~nm}$ excitation filter and a $535 \mathrm{~nm}$ emission filter. For the experiments with delayed addition of the antioxidants, cells were treated with glutamate $(2 \mathrm{~mm})$ for $8 \mathrm{~h}$, then the antioxidants were added for a further incubation of $2 \mathrm{~h}$. Afterwards, DCFA was added as described above.

\section{Brain Lipid Peroxidation}

Dissected cerebral cortex of adult Sprague-Dawley rats was homogenized in three volumes of degassed nonreducing lipid buffer (20 mM TRIS pH 7.4, 1 mM MgCl, 5 mM KCl) with a Kontes glass homogenizer. This and all subsequent steps were performed at $4{ }^{\circ} \mathrm{C}$. After centrifugation $(3000 \mathrm{~g}, 5 \mathrm{~min})$, the pellet was solubilized by sonication in lipid buffer supplemented with $0.5 \mathrm{M} \mathrm{NaCl}$, incubated for $30 \mathrm{~min}$, and centrifuged again (100 000 $g$, $20 \mathrm{~min}$ ). This step was repeated and followed by three analogous washing steps with water instead of lipid buffer. The resulting pellet was resuspended in water at a concentration of 5 $\mathrm{mg} / \mathrm{ml}$ protein and rapidly frozen at $-80^{\circ} \mathrm{C}$.

To determine the degree of lipid peroxidation with or without the cytoprotectants, low-level chemiluminescence was measured as an indicator of peroxidation reactions in progress. The rat brain membrane preparation was diluted with PBS to a concentration of $0.6 \mathrm{mg} / \mathrm{ml}$ protein and sonicated. Then the cytoprotective compounds were added to the aliquots as 1000 -fold stock solutions in ethanol. The oxidative chain reaction was initiated by addition of $50 \mu \mathrm{m}$ ascorbate and transfer to $37^{\circ} \mathrm{C}$. Six hours later, single photon counting was performed for 1 min with a Beckman scintillation counter, after decay of static electricity.

\section{ESR Spectroscopy}

Electron spin resonance spectra were measured on a Bruker ER-200 D-SRC spectrometer (TE 102 cavity), with a modulation frequency of $100 \mathrm{kHz}$, modulation amplitude of $0.8 \mathrm{G}$, sweep width of $100 \mathrm{G}$, center field of $3360 \mathrm{G}$, and microwave power of $5 \mathrm{~mW}$. Receiver gain was $5 \times 10^{5}$. Samples were prepared by coincubation of the spin trap $\mathrm{N}$-tert-butyl- $\alpha$-phenylnitrone (PBN; $50 \mathrm{~mm}$ ), the respective concentration of the aromatic imine, and the radical initiator tert-butyl hydroperoxide $(t-\mathrm{BuOOH} ; 100 \mathrm{~mm})$ in pure ethanol at a temperature of $75^{\circ} \mathrm{C}$ for $8 \mathrm{~h}$. The samples were then transferred to glass capillaries with an internal diameter of $0.9 \mathrm{~mm}$. The typical sample volume was $40-50 \mu l$. All spectra were acquired at room temperature.

\section{Computational Chemistry}

Molecular mechanics and semi-empirical quantum chemical calculations were performed employing the Chem3D software package. Geometry optimizations were done on the basis of a modified Allinger's MM2 force field routine. The semi-empirical MOPAC AM1 Hamiltonian was chosen for the subsequent calculation of the electronic levels (LUMO), the heats of formation $\left(H_{f}\right)$, and the spin densities $(\sigma)$. The energy minimizations were done to a minimum RMS gradient of 0.1. A microstate-improved, closed shell RHF approach was employed for the calculations, as implemented in MOPAC. All molecules, the parent compounds and the radicals were defined to be in ground state. For the determination of the octanol/water partition coefficients $(\log P)$, the Best Estimate method was used, which selects the literature fragmentation with the lowest standard deviation of estimate for the molecule of interest.

Employing $\Delta \mathrm{H}_{\mathrm{f}}$ and $\mathrm{E}(\mathrm{LUMO}$ ) ) to synthesize a bifactorial model for the compounds' antioxidant action, led to equation 1:

$$
\ln \left(E C_{50}\right)=-0.821+0.204 \times \Delta \mathrm{H}_{\mathrm{f}}+1.888 \times \mathrm{E}(\text { LUMOr })
$$

[number of data points $n=10$; adjusted correlation coefficient $r^{2}$ $=0.787$; standard error of estimate $\mathrm{s}=0.865(p=0.002)$; constant $=-0.821 \pm 2.698(p=0.770)$; coefficient $_{1}=0.204 \pm 0.0687$ $(p=0.021) ;$ coefficient $\left._{2}=1.888 \pm 0.726(p=0.035)\right]$.

Expanding this model by including $\log P$ and $\sigma(N)$, to build a quadrufactorial model, resulted in equation 2:

$$
\begin{aligned}
& \ln \left(\mathrm{EC}_{50}\right)=1.109+0.271 \times \Delta \mathrm{H}_{\mathrm{f}}+1.781 \times \mathrm{E}(\text { LUMOr })- \\
& 0.340 \times \log \mathrm{P}-12,687 \times \sigma(\mathrm{N})
\end{aligned}
$$

[number of data points $n=10$; adjusted correlation coefficient $r^{2}$ $=0.969$; standard error of estimate $s=0.331(p<0.001)$; constant $=1.109 \pm 1.074(p=0.349) ;$ coefficient $_{1}=0.271 \pm 0.0285(p$ $<0.001)$; coefficient $_{2}=1.781 \pm 0.286(p=0.002)$; coefficient $_{3}=$ $-0.340 \pm 0.0877(p=0.012)$; coefficient ${ }_{4}=-12.687 \pm 2.538(p=$ 0.004)].

In both models, the respective variables contributed to the equations independently, as indicated by the $p$-values given in brackets. The cross-correlation matrix revealed low interdependence of the four calculated physico-chemical parameters: $\Delta \mathrm{H}_{\mathrm{f}} v s \mathrm{E}\left(\right.$ LUMOr): $\mathrm{r}^{2}=0.555 ; \Delta \mathrm{H}_{\mathrm{f}}$ vs logP: $\mathrm{r}^{2}=0.099 ; \Delta \mathrm{H}_{\mathrm{f}} v s \sigma(\mathrm{N}):$ $r^{2}=0.363 ; E(L U M O r) v s$ logP: $r^{2}=0.152 ; E(L U M O r) v s \sigma(N): r^{2}=$ 0.192; log $\mathrm{P} v s \sigma(\mathrm{N}): \mathrm{r}^{2}=0.067$.

All statistical analyses and linear regression calculations were performed using the SigmaStat and SPSS software packages.

\section{Acknowledgements}

We would like to thank B. Nuscher for ESR technical assistance, and S. Montazeri and F. Gussmann for help with the slice culture experiments. We are also grateful to A. Breyer for help with the pharmacological assays, K. Hechenbichler for advice concerning statistics, and N. Bayatti for cell culture expertise and critical reading of the manuscript.

\section{References}

Alexi, T., Borlongan, C.V., Faull, R.L., Williams, C.E., Clark, R.G., Gluckman, P.D., and Hughes, P.E. (2000). Neuroprotective strategies for basal ganglia degeneration: Parkinson's and Huntington's diseases. Prog. Neurobiol. 60, 409-470.

Baker, K., Marcus, C.B., Huffman, K., Kruk, H., Malfroy, B., and Doctrow, S.R. (1998). Synthetic combined superoxide dismutase/catalase mimetics are protective as a delayed treatment 
in a rat stroke model: a key role for reactive oxygen species in ischemic brain injury. J. Pharmacol. Exp. Ther. 284, 215-221.

Behl, C. (1999). Alzheimer's disease and oxidative stress: implications for novel therapeutic approaches. Prog. Neurobiol. 57, 301-323.

Behl, C., Davis, J.B., Lesley, R., and Schubert, D. (1994). Hydrogen peroxide mediates amyloid $\beta$ protein toxicity. Cell 77 , 817-827.

Browne, S.E., Ferrante, R.J., and Beal, M.F. (1999). Oxidative stress in Huntington's disease. Brain Pathol. 9, 147-163.

Burton, G.W., le Page, Y., Gabe, E.J., and Ingold, K.U. (1980). Antioxidant activity of vitamin $E$ and related phenols: importance of stereoelectronic factors. J. Am. Chem. Soc. 102, $7791-7792$.

Busciglio, J., and Yankner, B.A. (1995). Apoptosis and increased generation of reactive oxygen species in Down's syndrome neurons in vitro. Nature $378,776-779$.

Christen, Y. (2000). Oxidative stress and Alzheimer disease. Am. J. Clin. Nutr. 71 (Suppl.), 621S-629S.

Cookson, M.R., and Shaw, P.J. (1999). Oxidative stress and motor neurone disease. Brain Pathol. 9, 165-186.

Dirnagl, U., ladecola, C., and Moskowitz, M.A. (1999). Pathobiology of ischemic stroke: an integrated view. Trends Neurosci. 22, 391-397.

Ebadi, M., Srinivasan, S.K., and Baxi, M.D. (1996). Oxidative stress and antioxidant therapy in Parkinson's disease. Prog. Neurobiol. 48, 1-19.

Fischer, H., Gottschlich, R., and Seelig, A. (1998). Blood-brain barrier permeation: molecular parameters governing passive diffusion. J. Membr. Biol. 165, 201-211.

Floyd, R.A. (1999). Antioxidants, oxidative stress, and degenerative neurological disorders. Proc. Soc. Exp. Biol. Med. 222, $236-245$

Foley, P., and Riederer, P. (2000). Influence of neurotoxins and oxidative stress on the onset and progression of Parkinson's disease. J. Neurol. 247 (Suppl. 2), II82 - 94.

Gilgun-Sherki, Y., Melamed, E., and Offen, D. (2001). Oxidative stress-induced neurodegenerative diseases: the need for antioxidants that penetrate the blood-brain barrier. Neuropharmacology 40, 959-975.

Grunblatt, E., Mandel, S., and Youdim, M.B. (2000). MPTP and 6-hydroxydopamine-induced neurodegeneration as models for Parkinson's disease: neuroprotective strategies. J. Neurol. 247 (Suppl. 2), II95-102.

Grundman, M. (2000) Vitamin E and Alzheimer disease: the basis for additional clinical trials. Am. J. Clin. Nutr. 71 (Suppl.), 630S-636S.

Gu, M., Owen, A.D., Toffa, S.E., Cooper, J.M., Dexter, D.T., Jenner, P., Marsden, C.D., and Schapira, A.H. (1998). Mitochondrial function, GSH and iron in neurodegeneration and Lewy body diseases. J. Neurol. Sci. 158, 24-29.

Gurney, M.E. (2000). What transgenic mice tell us about neurodegenerative disease. Bioessays 22, 297-304.

Gutzmann, H., and Hadler, D. (1998). Sustained efficacy and safety of idebenone in the treatment of Alzheimer's disease: update on a 2-year double-blind multicentre study. J. Neural Transm. 54 (Suppl.), $301-310$.

Halliwell, B. (2000). The antioxidant paradox. Lancet 335, $1179-1180$.

Harman, D. (1996). A hypothesis on the pathogenesis of Alzheimer's disease. Ann. NY Acad. Sci. 786, 152-168.

Huntington Study Group (1998). Safety and tolerability of the free-radical scavenger OPC-14117 in Huntington's disease. Neurology 50, 1366-1373.

Ishige, K., Schubert, D., and Sagara, Y. (2001). Flavonoids pro- tect neuronal cells from oxidative stress by three distinct mechanisms. Free Radic. Biol. Med. 30, 433-446.

Jung, C., Rong, Y., Doctrow, S., Baudry, M., Malfroy, B., and $\mathrm{Xu}$, Z. (2001). Synthetic superoxide dismutase/catalase mimetics reduce oxidative stress and prolong survival in a mouse amyotrophic lateral sclerosis model. Neurosci. Lett. 304, $157-160$.

Kamsler, A., Daily, D., Hochman, A., Stern, N., Shiloh, Y., Rotman, G., and Barzilai, A. (2001). Increased oxidative stress in ataxia telangiectasia evidenced by alterations in redox state of brains from Atm-deficient mice. Cancer Res. 61, 1849-1854.

Kaul, M., Garden, G.A., and Lipton, S.A. (2001). Pathways to neuronal injury and apoptosis in HIV-associated dementia. Nature 410, 988-994.

Leppala, J.M., Virtamo, J., Fogelholm, R., Albanes, D., and Heinonen, O.P. (1999). Different risk factors for different stroke subtypes: association of blood pressure, cholesterol, and antioxidants. Stroke 30, 2535-2540.

Lien, E.J., Ren, S., Bui, H., and Wang, R. (1999). Quantitative structure-activity relationship analysis of phenolic antioxidants. Free Radic. Biol. Med. 26, 285-294.

Lodi, R., Hart, P.E., Rajagopalan, B., Taylor, D.J., Crilley, J.G., Bradley, J.L., Blamire, A.M., Manners, D., Styles, P., Schapira, A.H., and Cooper, J.M. (2001). Antioxidant treatment improves in vivo cardiac and skeletal muscle bioenergetics in patients with Friedreich's ataxia. Ann. Neurol. 49, 590-596.

Louwerse, E.S., Weverling, G.J., Bossuyt, P.M., Meyjes, F.E., and de Jong, J.M. (1995). Randomized, double-blind, controlled trial of acetylcysteine in amyotrophic lateral sclerosis. Arch. Neurol. 52, 559-564.

Love, S. (1999). Oxidative stress in brain ischemia. Brain Pathol. 9, 119-131.

Milhavet, O., McMahon, H.E., Rachidi, W., Nishida, N., Katamine, S., Mange, A., Arlotto, M., Casanova, D., Riondel, J., Favier, A., and Lehmann, S. (2000). Prion infection impairs the cellular response to oxidative stress. Proc. Natl. Acad. Sci. USA 97, 13937-13942.

Moosmann, B., and Behl, C. (1999). The antioxidant neuroprotective effects of estrogens and phenolic compounds are independent from their estrogenic properties. Proc. Natl. Acad. Sci. USA 96, 8867-8872.

Moosmann, B., and Behl, C. (2000a). Cytoprotective antioxidant function of tyrosine and tryptophan residues in transmembrane proteins. Eur. J. Biochem. 267, 5687-5692.

Moosmann, B., and Behl, C. (2000b). Dietary phenols: antioxidants for the brain? Nutr. Neurosci. 3, 1-10.

Moosmann, B., and Behl, C. (2001). Antioxidants as treatment for neurodegenerative disorders. Exp. Opin. Invest. Drugs, in press.

Moosmann, B., Uhr, M., and Behl, C. (1997). Neuroprotective potential of aromatic alcohols against oxidative cell death. FEBS Lett. 413, 467-472.

Multhaup, G., Masters, C.L., and Beyreuther, K. (1998). Oxidative stress in Alzheimer's disease. Alzheimer's Reports 1 , $147-154$.

Nourhashemi, F., Gillette-Guyonnet, S., Andrieu, S., Ghisolfi, A., Ousset, P.J., Grandjean, H., Grand, A., Pous, J., Vellas, B., and Albarede, J.L. (2000). Alzheimer disease: protective factors. Am. J. Clin. Nutr. 71 (Suppl.), 643S-649S.

Ogawa, A., Yoshimoto, T., Kikuchi, H., Sano, K., Saito, I., Yamaguchi, T., and Yasuhara, H. (1999). Ebselen in acute middle cerebral artery occlusion: a placebo-controlled, double-blind clinical trial. Cerebrovasc. Dis. 9, 112-118.

Palau, F. (2001). Friedreich's ataxia and frataxin: molecular genetics, evolution and pathogenesis. Int. J. Mol. Med. 7, $581-589$. 
Parkes, T.L., Elia, A.J., Dickinson, D., Hilliker, A.J., Phillips, J.P., and Boulianne, G.L. (1998). Extension of Drosophila lifespan by overexpression of human SOD1 in motorneurones. Nature Genet. 19, 171-174.

Parkinson Study Group (1993). Effects of tocopherol and deprenyl on the progression of disability in early Parkinson's disease. N. Engl. J. Med. 328, 176-183.

Parnham, M., and Sies, H. (2000). Ebselen: prospective therapy for cerebral ischemia. Exp. Opin. Invest. Drugs 9, 607-619.

Prasad, K.N., Cole, W.C., Hovland, A.R., Prasad, K.C., Nahreini, P., Kumar, B., Edwards-Prasad, J., and Andreatta, C.P. (1999). Multiple antioxidants in the prevention and treatment of neurodegenerative disease: analysis of biologic rationale. Curr. Opin. Neurol. 12, 761-770.

Prasad, K.N., Hovland, A.R., Cole, W.C., Prasad, K.C., Nahreini, P., Edwards-Prasad, J., and Andreatta, C.P. (2000). Multiple antioxidants in the prevention and treatment of Alzheimer disease: analysis of biologic rationale. Clin. Neuropharmacol. 23, $2-13$.

Reiter, R.J. (1998). Oxidative damage in the central nervous system: protection by melatonin. Prog. Neurobiol. 56, 359-384.

Sano, M., Ernesto, C., Thomas, R.G., Klauber, M.R., Schafer, K., Grundman, M., Woodbury, P., Growdon, J., Cotman, C.W., Pfeiffer, E., Schneider, L.S., and Thal, L.J. (1997). A controlled trial of selegiline, alpha-tocopherol, or both as treatment for Alzheimer's disease. The Alzheimer's disease cooperative study. N. Engl. J. Med. 336, 1216-1222.

Sattler, R., and Tymianski, M. (2000). Molecular mechanisms of calcium-dependent excitotoxicity. J. Mol. Med. 78, 3-13.

Seelig, A., Gottschlich, R., and Devant, R.M. (1994). A method to determine the ability of drugs to diffuse through the bloodbrain barrier. Proc. Natl. Acad. Sci. USA 91, 68-72.

Shaw, P.J., and Eggett, C.J. (2000). Molecular factors underlying selective vulnerability of motor neurons to neurodegeneration in amyotrophic lateral sclerosis. J. Neurol. 247 (Suppl. 1), 117-27.

Shoulson, I. (1998). Datatop: a decade of neuroprotective inquiry. Parkinson study group. Deprenyl and tocopherol antioxidative therapy of parkinsonism. Ann. Neurol. 44 (Suppl. 1), S160-S166.

Sies, H. (1993). Ebselen, a selenoorganic compound as glu- tathione peroxidase mimic. Free Radic. Biol. Med. 14, $313-$ 323.

Sies, H. (1999). Glutathione and its role in cellular functions. Free Radic. Biol. Med. 27, 916-921.

Simonian, N.A., and Coyle, J.T. (1996). Oxidative stress in neurodegenerative diseases. Annu. Rev. Pharmacol. Toxicol. 36, 83-106.

Smith, K.J., Kapoor, R., and Felts, P.A. (1999). Demyelination: the role of reactive oxygen and nitrogen species. Brain Pathol. 9, $69-92$.

Sramek, J.J., and Cutler, N.R. (2000). Ongoing trials in Alzheimer's disease. Exp. Opin. Invest. Drugs 9, 899-915.

Tan, S., Wood, M., and Maher, P. (1998). Oxidative stress induces a form of programmed cell death with characteristics of both apoptosis and necrosis in neuronal cells. J. Neurochem. 71, 95-105.

van Acker, S.A., Koymans, L.M., and Bast, A. (1993). Molecular pharmacology of vitamin $\mathrm{E}$ : structural aspects of antioxidant activity. Free Radic. Biol. Med. 15, 311-328.

van Acker, S.A., de Groot, M.J., van den Berg, D.J., Tromp, M.N., den Kelder, G., van der Vijgh, W.J., and Bast, A. (1996). A quantum mechanical explanation of the antioxidant activity of flavonoids. Chem. Res. Toxicol. 9, 1305-1312.

Vatassery, G.T., Fahn, S., and Kuskowski, M.A. (1998). $\alpha$-Tocopherol in CSF of subjects taking high-dose vitamin $E$ in the Datatop study. Parkinson study group. Neurology 50, 19001902.

Wolozin, B., and Behl, C. (2000). Mechanisms of neurodegenerative disorders: control of cell death. Arch. Neurol. 57, $801-$ 804.

Wong, B.S., Pan, T., Liu, T., Li, R., Petersen, R.B., Jones, I.M., Gambetti, P., Brown, D.R., and Sy, M.S. (2000). Prion disease: a loss of antioxidant function? Biochem. Biophys. Res. Commun. 275, 249-252.

Yu, M.J., McCowan, J.R., Thrasher, K.J., Keith, P.T., Luttman, C.A., Ho, P.P., Towner, R.D., Bertsch, B., Horng, J.S., Um, S.L., Phebus, L.A., and Saunders, R.D. (1992). Phenothiazines as lipid-peroxidation inhibitors and cytoprotective agents. J. Med. Chem. 35, 716-724.

Received July 5, 2001; accepted September 6, 2001 